Research Article

\title{
Soil Quality Assessment Strategies for Evaluating Soil Degradation in Northern Ethiopia
}

\author{
Gebreyesus Brhane Tesfahunegn ${ }^{1,2}$ \\ ${ }^{1}$ College of Agriculture, Aksum University-Shire Campus, 314 Shire, Ethiopia \\ ${ }^{2}$ Center for Development Research (ZEF), University of Bonn, Walter-Flex Street No. 3, 53113 Bonn, Germany \\ Correspondence should be addressed to Gebreyesus Brhane Tesfahunegn; gebre33@gmail.com
}

Received 28 June 2013; Revised 17 November 2013; Accepted 22 November 2013; Published 4 February 2014

Academic Editor: William Horwath

Copyright (c) 2014 Gebreyesus Brhane Tesfahunegn. This is an open access article distributed under the Creative Commons Attribution License, which permits unrestricted use, distribution, and reproduction in any medium, provided the original work is properly cited.

\begin{abstract}
Soil quality (SQ) degradation continues to challenge sustainable development throughout the world. One reason is that degradation indicators such as soil quality index (SQI) are neither well documented nor used to evaluate current land use and soil management systems (LUSMS). The objective was to assess and identify an effective SQ indicator dataset from among 25 soil measurements, appropriate scoring functions for each indicator and an efficient SQ indexing method to evaluate soil degradation across the LUSMS in the Mai-Negus catchment of northern Ethiopia. Eight LUSMS selected for soil sampling and analysis included (i) natural forest (LS1), (ii) plantation of protected area, (iii) grazed land, (iv) teff (Eragrostis tef)-faba bean (Vicia faba) rotation, (v) teff-wheat (Triticum vulgare)/barley (Hordeum vulgare) rotation, (vi) teff monocropping, (vii) maize (Zea mays) monocropping, and (viii) uncultivated marginal land (LS8). Four principal components explained almost $88 \%$ of the variability among the LUSMS. LS1 had the highest mean SQI (0.931) using the scoring functions and principal component analysis (PCA) dataset selection, while the lowest SQI (0.458) was measured for LS8. Mean SQI values for LS1 and LS8 using expert opinion dataset selection method were 0.874 and 0.406 , respectively. Finally, a sensitivity analysis $(\mathrm{S})$ used to compare PCA and expert opinion dataset selection procedures for various scoring functions ranged from 1.70 for unscreened-SQI to 2.63 for PCA-SQI. Therefore, this study concludes that a PCAbased SQI would be the best way to distinguish among LUSMS since it appears more sensitive to disturbances and management practices and could thus help prevent further SQ degradation.
\end{abstract}

\section{Introduction}

Globally, declining in soil quality (SQ) has posed a tremendous challenge to increasing agricultural productivity, economic growth, and healthy environment $[1,2]$. The underlying causes for SQ degradation are largely related to inappropriate land use and soil management, erratic and erosive rainfall, steep terrain, deforestation, and overgrazing [2-4]. Most of the causes are resulted from a desperate attempt by farmers to increase production for the growing population which aggravate SQ degradation more in the developing countries, which mainly depend on natural resources (agriculture) $[1$, 4]. Misuse of natural resources that leads to degradation can also be stimulated by socioeconomic and political issues, for example, land tenure, capital, and infrastructure [5]. SQ degradation by soil erosion such as soil nutrient depletion and changes in soil physical indicators is largely recognized as a principal cause aggravated by the effect of inappropriate land use and soil management in the developing countries like Ethiopia [6, 7].

Interest in the evaluation of soil degradation particularly the quality of soil resources has been increased as soil is critically important component of the Earth's biosphere, functioning not only in the production of food and fibers but also in the maintenance of environmental quality [8]. In normal conditions, the soil can maintain equilibrium by pedogenetic processes [9-11]. However, this equilibrium is easily disturbed by anthropogenic activities (e.g., agricultural practices, deforestation, and overgrazing), and such effects are mainly noticed in the developing countries with poor 
technical and financial resources to manage natural resources $[10,11]$. In order to make sound decisions regarding sustainable land use systems, knowledge of SQ related to different land use scenarios is essential [12]. It is therefore most important to assess SQ degradation of different land use and soil management systems using soil quality index (SQI) since many of the factors that influence sustainable productivity are related to SQ. Information on SQI can support to further prioritization and then device management strategies that improve soil resources sustainably [11]. To do so, applying the concept of SQI is desirable as individual soil properties in isolation may not be sufficient to quantify changes in SQ related to land use and soil management systems [11, 13]. In line to this, many studies reported that indexing SQ indicators based on a combination of soil properties could better reflect the status of SQ degradation as compared to individual parameters $[6,13-15]$.

Despite the importance of SQI in describing SQ degradation or aggradations, there is no universally accepted dataset selection, scoring, and SQ indexing method for field conditions. Previous studies reported that different methods of minimum dataset selection (MDS), scoring, and SQ indexing have been applied but SQI results varied even for the same conditions $[11,13,16]$. The most widely reported MDS methods of SQ indicators are expert opinion and statistical tools (e.g., regression, principal component analysis (PCA)) $[11,13]$. An expert can generate a list of appropriate SQ indicators on the basis of ecosystem processes and functions and other decision rules such as management goals for a site associated with soil functions as well as other site-specific factors, like region or crop sensitivity as selection criteria $[13,16]$.

The transformation of the datasets into scores (scoring function) can be done using linear and nonlinear scoring techniques [11, 13]. Studies elsewhere compared the two scoring methods to represent soil system function but the value of nonlinear scoring method was reported higher than the linear method $[11,16,17]$. There are different types of linear and nonlinear scoring functions, even though none of the previous studies have evaluated them all simultaneously $[11,16]$. Different SQ indexing methods have been also used by different researchers [13, 16-18]. The same authors have reported that there are differences in SQI values among the various SQ indexing methods (e.g., additive, weighted, and max-min objective functions). Despite the fact that there is diversity in data selection, scoring, and SQ indexing methods, previous studies have limitation in evaluating the methods using the same data simultaneously in a similar field conditions.

Regardless of the above limitation, having SQI of longterm land use and soil management systems is necessary in order to locate areas to be carefully managed for sustainable development. The use of site-specific SQI can help planners and decision makers to evaluate which land use and management system is most sustainable and vice-versa in a given situation $[18,19]$. These authors also noted that SQI can reflect the extent of SQ degradation and thereby give support to suggest appropriate remedial measures such as optimum fertilizer rates and planning of other suitable land management practices considering potentials and constraints of different fields at large scale such as a catchment.

In general, SQI is a useful assessment tool that may help move soil conservation and resource management beyond assessments of soil erosion and changes in productivity [13]. SQI can thus provide the necessary information for planners and decision makers to make informed decisions against SQ degradation using the introduction of appropriate interventions. Despite such importance of SQI in combating SQ degradation, only few studies have been reported in relation to various land use and soil management systems. This indicated that research on SQI has been mostly neglected for unknown reasons, with the most probable reason which could be technical and financial limitations.

Many approaches assessing SQ degradation using the concept of SQI have been already developed and applied elsewhere [6, 11, 13, 15-19]. In this study, such concepts are adopted and evaluated to narrow the knowledge/information gap of SQI across different land use and soil management systems in the northern Ethiopia. The objective of this study was to assess and identify an effective SQ indicator dataset among 25 soil measurements, appropriate scoring functions for each indicator, and an efficient SQ indexing method to evaluate soil degradation across the LUSMS in the Mai-Negus catchment of northern Ethiopia.

\section{Materials and Methods}

2.1. Study Area. This evaluation was conducted in the MaiNegus catchment in Tigray regional state, northern Ethiopia (Figure 1). The catchment covers an area of 1240 ha, with a landscape consisting of generally rugged terrain at altitudes ranging from 2060 to $2650 \mathrm{~m}$ above sea level. Land use is dominantly arable with teff (Eragrostis tef) being the primary crop on $>80 \%$ of the land area. The remainder of the catchment is pasture with scattered patches of mixed tree, bush, and shrub cover. The major rock types are lava pyroclastic and metavolcanic. According to FAO-UNESCO Soil Classification System, soils are dominantly Leptosols at very steep positions, Cambisols on middle to steep slopes, and Vertisols on flat areas [20]. Annual rainfall averages $700 \mathrm{~mm}$ but is very erratic in amount and distribution throughout the catchment. Mean annual temperature was $22^{\circ} \mathrm{C}$.

2.2. Selection of Land Use and Soil Management Systems. Eight land use and soil management systems (LUSMS) were selected on the basis of three steps. First, information on historical and existing LUSMS in the catchment was collected and described. Soil sampling units were then identified across each LUSMS. Finally, composite soil samples were collected, processed, and analyzed for several SQ indicators using standard laboratory procedures. The first step is described below, with details for the second and third steps given in Sections 2.3 and 2.4 .

Field reconnaissance surveys and informal group discussions were conducted in June 2009 by the author, two development agents, and six farmers who are knowledgeable about the catchment and local farming systems. The six 


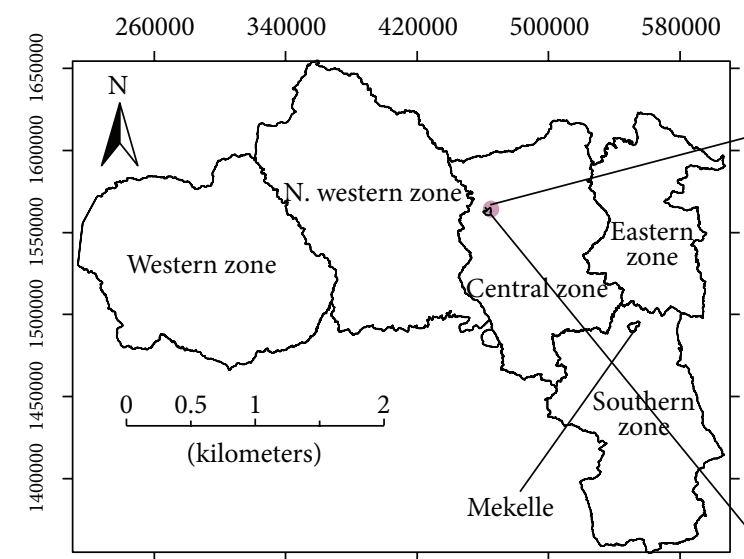

(b) Tigray

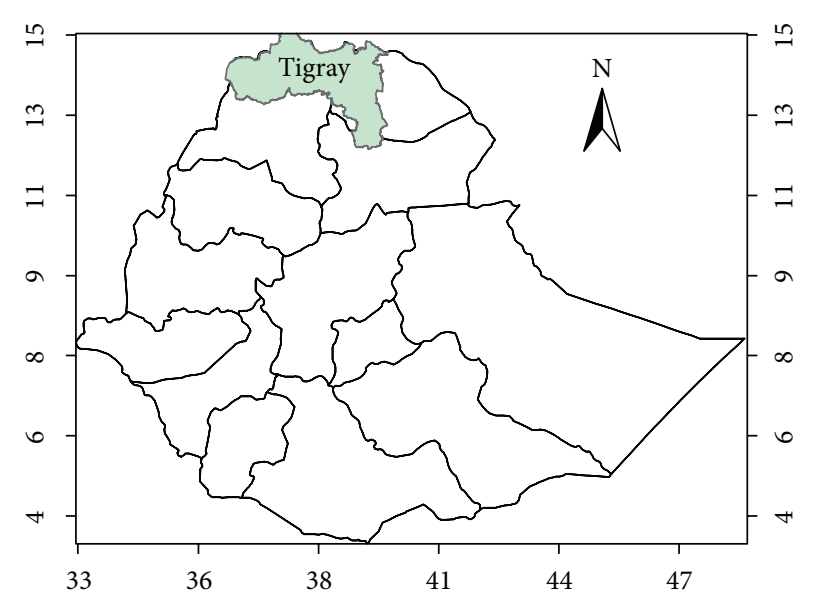

(a) Ethiopia

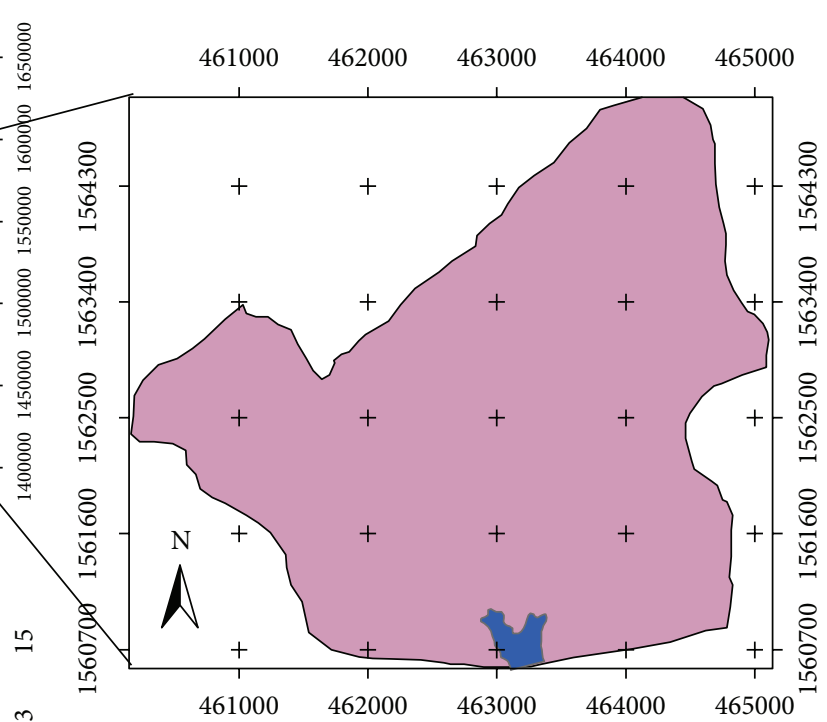

(c) Mai-Negus catchment

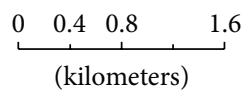

Projection: UTM Zone: $37 \mathrm{~N}$

Datum: Adindan Spheroid: Clarke 1880

Figure 1: Locations of the study area: Ethiopia (a), Tigray Region (b), and Mai-Negus catchment (study site) (c).

farmers were selected purposively because the large group size made it impractical for all the household heads to participate and doing so would have been problematic for discussion and consensus building. The dominant cropping history and soil management practices for each LUSMS were identified and described by the team. In addition, terrain characteristic and soil factors were documented for each rainfed agricultural LUSMS. All eight LUSMS were selected as much as possible to be from similar soil type (Cambisols) and a range in slope gradient in the catchment. Topographical characteristics of each sampling units are presented in Table 1.

Based on land use information acquired in the study, eight LUSMS that represent the best and worst management practices being used throughout the study catchment were identified and are described (Table 2). The LUSMS selected for SQ evaluation were (i) natural forest (LS1), (ii) plantation on protected areas (LS2), (iii) grazed land (LS3), (iv) teff (Eragrostis tef)-faba bean (Vicia faba) rotations (LS4), (v) teffwheat (Triticum vulgare)/barley (Hordeum vulgare) rotations (LS5), (vi) teff monocropping (LS6), (vii) maize (Zea mays) monocropping (LS7), and (viii) uncultivated marginal land (LS8). The various LUSMS were in place for various amounts of time ranging from 5 to 6 years for teff monocropping and 20 to 30 years for maize monocropping. Average age for the other systems was about 10 years except for the plantation, grazed land, and uncultivated marginal land with which was in place for more than 15 years. To assess the impact of LUSM on SQ indicators, it is either necessary to have a baseline against which human induced differences can be measured [21] or to measure the same systems repeatedly in time [13]. For this study, the researcher chose to use the natural forest (LS1) as a reference, assuming the soil in those areas is less disturbed than in cultivated or grazed areas.

2.3. Soil Sampling, Processing, and Analysis. After identifying the eight LUSMS locations, three soil sampling units and their corresponding areas were selected by the researcher considering representativeness and uniformity of the fields. Soil samples were collected from 24 areas (8 LUSMS $\times$ 3 sampling units) in June 2009 and analyzed for 24 potential SQ indicators. Each soil sampling unit ranged from 50 to $80 \mathrm{~m}^{2}$. Five to eight soil samples from 0 to $20 \mathrm{~cm}$ depth (plow layer) were collected randomly from each unit and mixed to form a composite sample. The number of composite samples 
TABLE 1: Topographic characteristics of each sampling unit in the eight LUSMS selected for soil quality assessment within the Mai-Negus catchment in northern Ethiopia.

\begin{tabular}{|c|c|c|c|c|c|c|c|c|c|c|c|c|}
\hline \multirow{3}{*}{ LUSMS } & \multicolumn{4}{|c|}{ Sampling Unit 1} & \multicolumn{4}{|c|}{ Sampling Unit 2} & \multicolumn{4}{|c|}{ Sampling Unit 3} \\
\hline & Elevation & \multirow{2}{*}{$\begin{array}{l}\text { Slope } \\
(\%)\end{array}$} & \multicolumn{2}{|c|}{$\mathrm{UTM}^{\mathrm{a}}$} & \multirow{2}{*}{$\begin{array}{l}\text { Elevation } \\
(\mathrm{m})\end{array}$} & \multirow{2}{*}{$\begin{array}{l}\text { Slope } \\
(\%)\end{array}$} & \multicolumn{2}{|c|}{ UTM } & \multirow{2}{*}{$\begin{array}{l}\text { Elevation } \\
(\mathrm{m})\end{array}$} & \multirow{2}{*}{$\begin{array}{l}\text { Slope } \\
(\%)\end{array}$} & \multicolumn{2}{|c|}{ UTM } \\
\hline & $(\mathrm{m})$ & & Latitude & Longitude & & & Latitude & Longitude & & & Latitude & Longitude \\
\hline LS1 & 2175 & 7 & 463657 & 1561482 & 2170 & 5.5 & 463856 & 1561592 & 2173 & 6.2 & 464039 & 1561523 \\
\hline LS2 & 2124 & 4.5 & 463383 & 1560411 & 2152 & 5 & 463615 & 1560503 & 2138 & 5.5 & 463248 & 1560503 \\
\hline LS3 & 2136 & 5 & 463425 & 1561193 & 2165 & 5.5 & 463489 & 1561466 & 2151 & 5.0 & 463535 & 1561614 \\
\hline LS4 & 2168 & 6 & 463592 & 1561250 & 2145 & 6.5 & 462538 & 1561454 & 2157 & 6.0 & 463168 & 1561832 \\
\hline LS5 & 2141 & 6.5 & 463606 & 1561338 & 2163 & 7 & 463317 & 1561763 & 2152 & 6.8 & 463707 & 1561912 \\
\hline LS6 & 2165 & 6 & 463734 & 1561459 & 2136 & 5.5 & 463363 & 1561500 & 2151 & 5.8 & 464124 & 1561328 \\
\hline LS7 & 2162 & 6.5 & 462810 & 1561314 & 2155 & 7 & 462641 & 1561614 & 2159 & 6.8 & 464027 & 1561202 \\
\hline LS8 & 2149 & 7 & 462795 & 1561152 & 2138 & 5 & 462745 & 1561718 & 2144 & 6.0 & 463913 & 1562153 \\
\hline
\end{tabular}

aniversal Transverse Mercator 37 North (UTM-37N) in meters is the projection system.

LUSMS: land use and soil management systems; LS1: natural forest (reference); LS2: plantation of protected area; LS3: grazed land; LS4: teff (Eragrostis tef)faba bean (Vicia faba) rotation; LS5: teff-wheat (Triticum vulgare)/Barley (Hordeum vulgare) rotation; LS6: teff monocropping; LS7: Maize (Zea mays) monocropping; LS8: uncultivated-marginal land system.

was determined by the size and homogeneity (hydrologic conditions) of each sampling unit. Fewer samples were collected from homogenous, small fields compared to large, heterogeneous fields. The sampling focused on the plow layer because this is where most SQ changes are expected to occur due to long-term land use and soil management practices. Each composite soil sample was mixed thoroughly in a bucket before taking a $500 \mathrm{~g}$ subsample that was air dried and sieved to pass a $2 \mathrm{~mm}$ mesh before analysis.

The soil samples were analyzed for selected physical, chemical, and biological SQ indicators. Soil texture was determined using the Bouyoucos hydrometer method [22] and soil bulk density (BD) by the core method [23]. Percent pore space (total porosity) was computed from $\mathrm{BD}$ and average particle density (PD) of $2.65 \mathrm{~g} \mathrm{~cm}^{-3}$ as $\{1-\mathrm{BD} / \mathrm{PD}\} \times$ 100 [24]. Soil aggregate stability (SAS) was measured using the wet sieve method [25] and maximum water holding capacity (MWHC) determined by equilibrating the soil with water through capillary action in a KR box [26]. A-horizon depth was directly measured in pits opened to a $60 \mathrm{~cm}$ depth within each LUSMS.

Soil $\mathrm{pH}$ was determined using a $1: 2.5$ soil to water ratio with a combined glass electrode [27]. Soil organic (OC) was determined by the Walkley-Black method [28], available phosphorus (Pav) by the Olsen method [29], total nitrogen (TN), and total phosphorus (TP) by the Kjeldahl digestion method [30]. Cation exchange capacity (CEC) was determined by ammonium acetate buffered at $\mathrm{pH} 7$ [31]. Exchangeable bases (calcium, Ca; magnesium, $\mathrm{Mg}$; potassium, $\mathrm{K}$ ) were analyzed after extraction using $1 \mathrm{M}$ ammonium acetate at $\mathrm{pH}$ 7.0. Iron and zinc were determined using $0.005 \mathrm{M}$ diethylene triamine pentaacetic acid (DTPA) extraction as described in Baruah and Barthakur [26].

Exchangeable sodium percentage (ESP) was calculated by dividing exchangeable $\mathrm{Na}^{+}$by CEC. Base saturation percentage (BSP) was calculated by dividing the sum of base forming cations by CEC, multiplied by $100 \%$ [32]. A 25th SQ indicator, earthworm population, was monitored monthly as
(1) Indicator selection

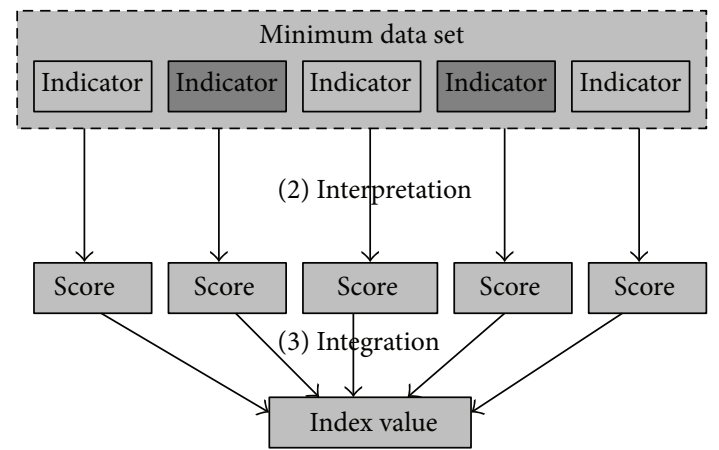

FIgURE 2: A conceptual model for computing soil quality indices. (From Andrews [33].)

a biological indicator throughout the wet season (mid-Junemid-September 2009). Three randomly collected soil samples $(25 \times 25 \times 20 \mathrm{~cm})$ from a $1 \mathrm{~m}^{2}$ area were passed through a $10 \mathrm{~mm}$ sieve to separate and then count the average number of earthworms in each LUSMS sampling unit.

2.4. Soil Quality Index Computations. After measuring the 25 potential SQ indicators using field and laboratory analysis techniques, different methods for computing SQI values were evaluated. Although the type of data used for each SQI may differ, the process of $S Q$ indexing follows the same three basic steps regardless of the method used (Figure 2). These steps are indicator selection, interpretation/scoring, and integration into index value $[11,33]$. The detailed descriptions of each step are given below.

2.4.1. Indicator Selection (Step 1). Potential SQ indicators were selected based on their sensitivity to management practices, ability to describe major soil processes, ease and cost of sampling and laboratory analysis, and significance 
TABLE 2: Description of the eight land use and soil management systems (LUSMS) evaluated within the Mai-Negus catchment in northern Ethiopia.

\begin{tabular}{lcl}
\hline Serial number & Land use and soil management systems & Description \\
\hline 1 & Natural forest (LS1) & $\begin{array}{l}\text { Less disturbed land, used as a reference in the system, which has native trees, } \\
\text { vegetation, and grass cover. }\end{array}$ \\
\hline \multirow{2}{*}{ Plantation of protected area (LS2) } & $\begin{array}{l}\text { Sesbania (Sesbania sesban) and Leucaena (Leucaena leucocephala) trees } \\
\text { plantation was established 16 years ago and grass was used by cuting and } \\
\text { carrying during the dry season for livestock, protected throughout the year } \\
\text { from livestock interferences; no fertilizer application and less intensive soil } \\
\text { conservation measures exist. }\end{array}$ \\
\hline
\end{tabular}
conservation measures exist.

$3 \quad$ Grazed land (LS3)

Open grazed land appeared during the dry season 16 years ago with no inclusion of any improved management practices, for example, soil and water conservation and enrichment of plant/grass species. It overstocked in the dry months (November-June) but it is a swampy area for the rest of months.

Fields were harvested of teff (Eragrostic tef (Zucc) Trot) crop before soil samples were collected and rotated with faba bean (Vicia faba $L$.) for more than 5-6 years. Urea and diammonium phosphate (DAP) fertilizers were applied each for teff at $50 \mathrm{~kg} \mathrm{ha}^{-1} \mathrm{y}^{-1}$ but sometimes reduced by half

Teff (Eragrostis tef)-faba bean (Vicia faba) rotation (LS4)

5

Teff-wheat (Triticum vulgare)/Barley

(Hordeum vulgare) rotation (LS5)

6

${ }^{\mathrm{a}}$ Teff mono-cropping land system (LS6)

7

Maize (Zea mays L.)-mono cropping land system (LS7)

8

Uncultivated marginal land system (LS8)

depending on resource availability and quality of the soil. Teff needed 4-6

times tillage and at least one time weeding. For faba bean, 2-3 times tillage was sufficient with no or one time weeding and addition of manure around homestead is common practice but is urea or DAP rarely used. Soil and water conservation was used at field borders.

The fields were planted wheat (Tritium vulgare L.) before teff (Eragrostic tef (Zucc) Trot) and soil samples were collected after teff was harvested. Wheat (Triticum vulgare L.)/barley (Hordeum vulgare L.) with teff (Eragrostic tef) was rotated for more than 6 years. $50 \mathrm{~kg} \mathrm{ha}^{-1} \mathrm{y}^{-1}$ of each urea and DAP fertilizers was used for teff field but the amount varies with crop color at vegetative stage and soil quality condition for fertilizer rate application on wheat/barley crop fields. The fertilizer rate used for wheat/barley is lower than teff.

For more than 5-6 years, teff (Eragrostic tef (Zucc) Trot) was sown continuously with $50 \mathrm{~kg} \mathrm{ha}^{-1} \mathrm{y}^{-1}$ urea and $100 \mathrm{~kg} \mathrm{ha}^{-1} \mathrm{y}^{-1}$ DAP fertilizers; 5-7 tillage frequency; at least one time hand weeding. Manure and intensive SWC for fields around homestead was applied.

Maize (Zea mays L.) was planted for more than 20-30 years continuously. The addition of manure was estimated at $6-12 \mathrm{tha}^{-1} \mathrm{y}^{-1}$, which varies with manure and labor availability for transportation; 2-3 tillage frequency with at least one times hand hoeing and weeding. This is always practiced around homestead fields. Conservation measures are also well executed.

It was terraced with wide spacing since the last 20 years but most of it is broken and used as an open grazing land throughout the year; on some spot areas it had very few to few naturally growing but over grazed grass species like Bermuda grass (Cynodon dactylon L.) management practices such as fertilizer and species enrichment were not introduced. Farmers considered it as the most degraded soil, for example, abandoned land.

${ }^{a}$ Teff is the dominant crop in the study catchment and other parts of northern Ethiopia. It is an annual cereal crop (belonging to the grass family) which has sparse crop canopies and provides little cover to the soil against erosion. It has very fine seeds that require repeated plowing of fields and preparation of fine seedbeds, which increases the vulnerability of the soil to erosion.

of increasing productivity (agronomic) and protecting environmental soil functions. Two methods for selecting a minimum dataset (MDS), expert opinion (EO), and principal component analysis (PCA) were compared. For the EO approach MDS, variables were chosen from the 25 potential SQ indicators based on researcher knowledge and literature recommendations [34-36].

2.4.2. Indicator Transformation/Scoring Function (Step 2). After selecting the MDS using EO or PCA (Step 1), each value was transformed using two different scoring techniques
$[11,33]$. Both linear and nonlinear scoring functions were compared as described below.

(I) Linear Scoring Functions. Three linear scoring functions (LSF) were identified and evaluated. For the first LSF approach, indicators were ranked in ascending for "more is better" or descending order for "less is better" in terms of soil functions [37]. Each "more is better" indicator was divided by the highest value in the group such that it received a score of 1 . For "less is better" indicator with the lowest observed value, it was divided by itself so that it received a score of 1. Threshold values were identified and used as outlined by 
TABLE 3: Soil quality indicators, scoring curve, and threshold and baseline limits used for evaluating eight LUSMS in northern Ethiopia.

\begin{tabular}{|c|c|c|c|c|c|c|c|}
\hline \multirow{2}{*}{ Indicator } & \multirow{2}{*}{ Scoring curve } & \multicolumn{2}{|c|}{ Threshold } & \multirow{2}{*}{ Baseline $^{c}$} & \multirow{2}{*}{ Optimum $^{\mathrm{d}}$} & \multirow{2}{*}{ Slope at baseline } & \multirow{2}{*}{ Source of limits } \\
\hline & & Lower $^{\mathrm{a}}$ & Upper $^{\mathrm{b}}$ & & & & \\
\hline \multirow{2}{*}{ Sand (\%) } & \multirow{2}{*}{ Optimum } & \multirow{2}{*}{0} & \multirow{2}{*}{60} & $\mathrm{~L}, 30$ & \multirow{2}{*}{36} & \multirow{2}{*}{0.440} & \multirow{2}{*}{$\begin{array}{l}\text { Natural ecosystem, best managed } \\
\text { soils }\end{array}$} \\
\hline & & & & $\mathrm{U}, 50$ & & & \\
\hline Silt (\%) & More is better & 0 & 38 & 19 & - & 0.249 & $\begin{array}{l}\text { Best managed soil, natural } \\
\text { ecosystem }\end{array}$ \\
\hline Clay (\%) & More is better & 0 & 31 & 15 & - & 0.268 & Natural ecosystem \\
\hline SAS (\%) & More is better & 10 & 60 & 30 & - & 0.296 & Harris et al. [17]; natural system \\
\hline $\mathrm{BD}\left(\mathrm{g} \mathrm{cm}^{-3}\right)$ & Less is better & 1 & 2.2 & 1.5 & 1.2 & -0.323 & Harris et al. [17]; natural ecosystem \\
\hline A-horizon depth (cm) & More is better & 0 & 20 & 10 & - & 0.318 & Natural ecosystem \\
\hline MWHC (\%) & More is better & 20 & 58 & 30 & - & 0.198 & Gregory et al. [41]; natural system \\
\hline $\mathrm{OC}^{\mathrm{e}}(\%)$ & More is better & 1 & 6.5 & 3.5 & - & 1.046 & $\begin{array}{l}\text { Kay and Angers [42]; natural } \\
\text { ecosystem }\end{array}$ \\
\hline $\operatorname{CEC~}\left(\mathrm{cmol}_{\mathrm{c}} \mathrm{kg}^{-1}\right)$ & More is better & 6 & 46 & 20 & - & 0.245 & $\begin{array}{l}\text { Natural ecosystem, best managed } \\
\text { soil }\end{array}$ \\
\hline $\mathrm{TN}(\%)$ & More is better & 0.05 & 0.54 & 0.30 & - & 25.408 & Natural ecosystem, \\
\hline $\mathrm{TP}\left(\mathrm{mg} \mathrm{kg}^{-1}\right)$ & More is better & 200 & 1316 & 650 & - & 0.005 & Natural ecosystem \\
\hline $\operatorname{Pav}\left(\mathrm{mg} \mathrm{kg}^{-1}\right)$ & More is better & 5 & 29 & 15 & - & 0.433 & $\begin{array}{l}\text { Mausbach and Seybold [43]; natural } \\
\text { ecosystem }\end{array}$ \\
\hline \multirow[t]{2}{*}{$\mathrm{Zn}\left(\mathrm{mg} \mathrm{kg}^{-1}\right)$} & \multirow[t]{2}{*}{ Optimum } & \multirow[t]{2}{*}{2} & \multirow[t]{2}{*}{20} & $\mathrm{~L}, 10$ & \multirow[t]{2}{*}{14} & \multirow[t]{2}{*}{0.855} & \multirow{2}{*}{$\begin{array}{l}\text { Mausbach and Seybold [43]; natural } \\
\text { system }\end{array}$} \\
\hline & & & & $\mathrm{U}, 18$ & & & \\
\hline \multirow[t]{2}{*}{$\mathrm{Fe}\left(\mathrm{mg} \mathrm{kg}^{-1}\right)$} & \multirow[t]{2}{*}{ Optimum } & \multirow[t]{2}{*}{10} & \multirow[t]{2}{*}{50} & $\mathrm{~L}, 20$ & \multirow[t]{2}{*}{26} & \multirow[t]{2}{*}{0.577} & \multirow[t]{2}{*}{ Harris et al. [17]; natural system } \\
\hline & & & & $\mathrm{U}, 40$ & & & \\
\hline $\begin{array}{l}\text { Earth worm count } \\
\text { per } \mathrm{m}^{2}\end{array}$ & More is better & 0 & 11 & 5 & - & 0.470 & Natural ecosystem \\
\hline
\end{tabular}

${ }^{\text {a }}$ Soils at or below the threshold values are prone to structural destabilization, erosion, and low productivity; so the scoring value is 0.

${ }^{\mathrm{b}}$ Soils at or beyond this values no further increase in productivity or decrease in erosion rate are achieved the upper threshold; values at and above this level thus receive a score of 1.0 .

${ }^{\mathrm{c}}$ Values receive a score of 0.5 and are generally regarded as the minimum target values.

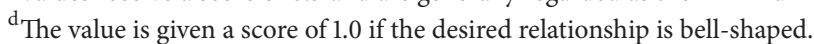

${ }^{\mathrm{e}}$ According to Kay and Angers [42], irrespective of soil type if SOC contents are below 1\%, it may not be possible to obtain potential yields.

L: lower; U: upper; SAS: soil aggregate stability; BD: bulk density; MWC: maximum water holding capacity; OC: organic carbon; CEC: cation exchangeable capacity; TN: total nitrogen; TP: total phosphorous; Pav: available phosphorous; Zn: available Zinc; Fe: available iron; - : implies not applicable.

Liebig et al. [37]. This approach $\left(\mathrm{I}^{\mathrm{L}}\right)$ was therefore described as the "Liebig Linear Scoring Function."

For the second LSF approach, SQ indicator values were transformed to a common range between 0.1 and 1.0 using homothetic transformation equations (1) and (2) [38]. In the context of this study, this is termed as "homothetic transformation method of LSF" $\left(\mathrm{II}^{\mathrm{L}}\right)$ :

$$
\begin{aligned}
& Y=0.1+\left(\frac{(X-b)}{(a-b)}\right) * 0.9 \\
& Z=1-\left(\frac{(X-b)}{(a-b)}\right) * 0.9
\end{aligned}
$$

where $Y$ and $Z$ are values of the variables after transformation. $X$ is value of the variable to transform and $a$ and $b$ are the maximum and minimum threshold values of the variable (Table 3). Equation (1) is used for "more is better" scoring function, (2) for "less is better," and a combination of both equations for "optimum is better" scoring function.
This LSF approach is therefore described as the "homothetic transformation method" (II $\left.{ }^{\mathrm{L}}\right)$.

The third LSF approach was adopted from Masto et al. [11], Glover et al. [39], and Masto et al. [40]. It is described as

$$
\begin{gathered}
(Y)=\frac{(x-s)}{(t-s)}, \\
(Y)=1-\frac{(x-s)}{(t-s)},
\end{gathered}
$$

where $Y$ is the linear score, $x$ is the soil property value, and $s$ and $t$ are lower and upper threshold values (Table 3 ). For values below and above the threshold, the score is zero. Equation (3) was used for "more is better," whereas (4) for "less is better" and a combination of both for "optimum is better." This approach is therefore described as "Glover LSF method" (III $\left.{ }^{\mathrm{L}}\right)$.

(II) Nonlinear Scoring Functions. Two nonlinear scoring function (NLSF) approaches were also evaluated. The first NLSF approach transformed the indicators using 
curves constructed with CurveExpert version 1.3 shareware (http://www.flu.org.cn/en/download-79.html) as described by Andrews et al. [13]. The shape of each curve, that is, bell-shaped (midpoint is optimum), sigmoid with an upper asymptote (more is better) or sigmoid with a lower asymptote (less is better), was determined according to agronomic and environmental soil functions using data from undisturbed fields (natural ecosystem), literature values, and knowledge of experts. To develop indicator curve using CurveExpert, it was assumed that levels of activity found in undisturbed soil (natural forest) would have a score at or near 1.0. Polynomial fit model was applied after examining the data by curve finder and then drawing the curve based on the observed values of SQ indicators from undisturbed ecosystem. After interpolated by polynomial Lagrangian interpolation method in the CurveExpert version 1.3, the corresponding transformed value was analyzed for each untransformed indicator value in each LUSMS. The $X$-axis for the functions represented a site-specific expected range of values of the soil properties. The $Y$-axis, ranging from 0 to 1 , was the transformed score. This approach is termed as the "CurveExpert method of NLSF" $\left(\mathrm{I}^{\mathrm{N}}\right)$.

The second NLSF used (5) to normalize SQ indicators suggested by Masto et al. [11]; Glover et al. [39]; Masto et al. [40] and is therefore termed as the "GloverNLSF method" $\left(\mathrm{II}^{\mathrm{N}}\right)$ :

$$
\operatorname{NLSF}(Y)=\frac{1}{\left[1+e^{-b(x-A)}\right]},
$$

where $x$ is the indicator value, $A$ is the baseline or value of the soil property where the score equals 0.5 or about the midpoint between the upper and lower threshold value, and $b$ is the slope. Baseline values are generally regarded as the minimum target value. If soil indicator values are located within the control limits, the system is considered to be in an acceptable state. Conversely, if the values lie outside the threshold limits, the system is considered to be in a state of degradation [11, 40, 44].

Critical values or thresholds were established based on a range of values measured in natural ecosystems, best managed systems, and values adopted from literatures and personal experiences of the researcher to better fit to the local conditions within the catchment (Table 3 ). This table also presents the indicator scoring curve, baseline, and threshold values used to transform selected SQ indicators. For detailed descriptions of these standard scoring functions the reader is referred to Masto et al. [11]; Glover et al. [39]; Masto et al. [40]; Karlen et al. [45].

Measured values are transformed into unitless scores ranging from 0 to 1 so that scores can be combined and averaged into a single value such that a score of 1 represents the highest potential function for that system; that is, the indicator is nonlimiting with regard to the pertinent soil functions and processes [46]. An advantage of indexing is that important information can often be captured by scoring that might otherwise go undetected when examining only the observed values [13].
2.4.3. Soil Quality Indexing (Step 3). Two SQ indexing methods are commonly found in literature, for example, Masto et al. [11]; Glover et al. [39]; Masto et al. [40]. The first is unscreened transformation (the additive index) and the second uses principal component analysis (PCA). Both methods were applied to data from each LUSMS. The SQI values were then compared with those from natural forest land systems to assess the degree of soil degradation or improvement. Details of the two SQ indexing methods are summarized below.

(I) Unscreened Transformation Based Soil Quality Indexing (Unscreened-SQI). SQ indicators are integrated into an index (SQI) by summing the scores from individual indicators and dividing by the total number of indicators (i.e., an additive model) as described in Masto et al. [40]:

$$
\text { unscreened SQI }=\left(\frac{\sum_{i=1}^{n} S_{i}}{n}\right),
$$

where SQI is the soil quality index, $S$ is the linear or nonlinear scored value of individual indicators, and $n$ is the number of indicators included in the dataset.

(II) Principal Component Analysis Based Soil Quality Indexing (PCA-SQI). A standard PCA was conducted using all SQ indicators that showed significantly differences among the LUSMS. Under each principal component (PC), only the variables having high factor loadings and eigenvalues $>1$ that explained at least $5 \%$ of the data variations were retained for indexing. Among well-correlated variables within each PC, the variable with the highest correlation coefficient (absolute value) and loading factor was chosen. If the highly weighted variables ( $\geq \pm 0.7$ eigenvector) were not well correlated ( $r<$ 0.60 ), each was considered important and retained in the PC for SQ indexing. As each PC explains a certain amount of variation within the total dataset, this provides a "weight" for the variables chosen under a given PC. The final PCA based SQI (7) described by Masto et al. [40] was used for this study:

$$
\text { PCA-SQI }=\sum_{i=1}^{n} W_{i} S_{i},
$$

where PCA-SQI is principal component analysis (PCA) based soil quality index, $W_{i}$ is the PCA weighing factor equal to the ratio of variance of each factor to total cumulative variance coefficients in the equation, and $S_{i}$ is scored value of each SQ indicator.

2.5. Evaluation of Soil Quality Indexing Methods. The SQ indexing methods were evaluated using sensitivity analysis described by Masto et al. [11] as

$$
\text { Sensitivity }(S)=\frac{\operatorname{SQI}_{(\max )}}{\operatorname{SQI}_{(\min )}},
$$

where $S Q I_{(\max )}$ and $S Q I_{(\min )}$ are the maximum and minimum SQI observed under each scoring procedure using each dataset selection methods. The SQ indexing method with higher value of sensitivity is more preferable as this is sensitive to perturbations and management practices [21]. 
2.6. Data Analysis. Data were analyzed using statistical software package of SPSS 18.0 [47]. One-way analysis of variance (ANOVA) was performed to determine the effects of LUSMS on SQI. Mean SQI was tested for its level of significance at probability level $(P) \leq 0.05$. Data were also analyzed using correlation and factor analysis. A PCA was used to examine the relationship among the 24 SQ indicators by statistically grouping them into four PC factors through the varimax rotation procedure. Varimax rotation with Kaiser Normalization was used because this results in a factor pattern that highly loads into one factor [48]. Communalities estimate the portion of variance of each soil attribute that explains for the factors. A high communality for a soil attribute indicates a high proportion of the variance explained in the factor. Less importance should be ascribed to soil attributes with low communalities when interpreting the factors [48].

\section{Results and Discussion}

3.1. Grouping Soil Quality Indicators. A moderate to strong correlation $(r>0.7)$ among many SQ indicators within the different LUSMS was observed, indicating a multicollinearity effect (data not shown). Factor analysis can help reduce the number of indicators analyzed needed for indexing by identifying components that best account for the variability and thus minimizing data redundancy (multicollinearity effect). The 25 SQ indicators analyzed to evaluate the eight LUSMS were grouped using a PCA. This resulted in four principal component (PC) groups that best explained variability in the data (Table 4). Communalities of the SQ indicators (Table 4) show that individual indicators accounted for 64 to $97 \%$ of the variance. Indicators with high communality get preference over those with low communality [49]. When combined, the first four PCs factors with eigenvalues $>1$ explained about $88 \%$ of the soil variability among the eight LUSMS. The first two PCs accounted for about $52 \%$ of the variance, indicating that these would be potential components to assess SQ effects within the LUSMS.

Eigenvectors for the first four PCs (Table 4) show that OC, TN, EW, porosity, and $\mathrm{Zn}$ were retained for PC1. The correlation coefficient between $\mathrm{TN}$ and the other variables was less than 0.6 , so TN was retained in PC1. However, the high correlation coefficient $(r>0.87)$ of OC with the other high loading variables suggested that OC was most important so it too was retained in PC1 for SQ indexing. Several literature references show that EW populations are highly influenced by organic matter availability [50, 51]. Furthermore, according to Jenkinson [52], soil microbial biomass comprises 1 to $4 \%$ of the total OC and 2 to $6 \%$ of the total organic nitrogen. Based on this information, we chose to exclude EW data from PC1 since its contribution is explained by soil organic matter. For such reasons, $\mathrm{PCl}$ is referred to as the "soil organic matter factor."

Soil CEC, TP, exchangeable $\mathrm{K}$ and $\mathrm{Ca}$ were the highly loaded factors attributed to PC2. The CEC values were strongly correlated $(r=0.85)$ with $\mathrm{K}$, and $\mathrm{Ca}$ so $\mathrm{CEC}$ was selected as the preferred variable for retention in PC2.
The correlation coefficient of TP with the other variables was $<0.6$ and since the cutoff is $r=0.7$, TP was also retained in PC2. Phosphorus is frequently a limiting factor for crop production in northern Ethiopia soils, so its inclusion in a SQ index is logical for assessing SQ degradation within the various LUSMS. Based on these two factors, PC2 is referred to as the "soil macro-nutrient factor."

The only highly loaded variables in PC3 were silt, DBD, and $\mathrm{pH}$. The correlation of silt with the highly loaded variables was less than 0.6 , so it was retained in PC3 for index development. A similar analysis showed a higher partial correlation for DBD $(r>0.80)$, indicating that it was also a preferred indicator for retention in PC3. Both silt and DBD also showed higher communality effect when compared to $\mathrm{pH}$. These indicators also influenced the SQ in an opposite direction (Table 4); their inclusion in any SQ indexing is crucial to assess variability associated with the various LUSMS. Again, based on the critical indicators, PC3 is referred to as the "soil physical property factor." The fourth PC is referred to as the "soil micro-nutrient factor," because Fe is the highly loaded variable (Table 4).

Based on the four PCs, a composite PCA-SQI consisting of soil OC, TN, CEC, TP, silt, DBD, and Fe was chosen to assess SQ variability among the LUSMS. Weighting factors were developed based on the percent variation explained by the first four PCs (Table 4), resulting in a final normalized PCA based SQI equation:

$$
\begin{aligned}
\text { PCA-SQI }= & 0.190_{\mathrm{OC}}+0.190_{\mathrm{TN}}+0.135_{\mathrm{CEC}}+0.135_{\mathrm{TP}} \\
& +0.125_{\text {silt }}+0.125_{\mathrm{DBD}}+0.100_{\mathrm{Fe}},
\end{aligned}
$$

where PCA-SQI is a PCA based soil quality index and $S$ is the score (linear or nonlinear) for each variable (Table 4), with coefficients based on the variance accounted for by each PC.

\subsection{Integration of Soil Quality Indicators into a Soil Quality Index}

3.2.1. Unscreened Transformation Based Soil Quality Index (Unscreened-SQI). An unscreened-SQI using the PCA and EO selected minimum datasets showed the highest SQI values for the $\mathrm{II}^{\mathrm{L}}$ (homothetic transformation method) and $\mathrm{I}^{\mathrm{N}}$ (CurveExpert method of NLSF) models used to compare the eight LUSMS (Tables 5 and 6). For all comparisons, the nonlinear unscreened-SQI showed higher values than the linear scored functions. In addition, unscreened-SQI values for both LSF and NLSF methods were greater for EO minimum datasets than for PCA selected datasets.

Among LUSMS, LS1 had a significantly higher $(P \leq 0.05)$ unscreened-SQI value whereas a lower value in LS8 using either the PCA or EO selected datasets. The general SQI pattern among the LUSMS was LS1 > LS2 > LS7 > LS4 > LS3 > LS5 > LS6 > LS8, (Tables 5 and 6). Mean unscreenedSQI differences between the LS1 reference soils and average unscreened-SQI values for PCA and EO datasets showed the following soil degradation levels: LS2 (-8\%), LS3 (-20\%), LS7 $(-24 \%)$, LS4 (-26\%), LS6 (-38\%), LS5 (-45\%), and LS8 $(-58 \%)$. Generally, this study demonstrated that LS2 followed 
TABLE 4: Principal component analysis results using 25 potential soil quality indicators to evaluate eight LUSMS in the Mai-Negus catchment, northern Ethiopia.

\begin{tabular}{|c|c|c|c|c|c|}
\hline \multirow{2}{*}{ Eigenvector } & \multicolumn{4}{|c|}{ Principal component, $\mathrm{PC}$} & \multirow{2}{*}{ Communalities } \\
\hline & 1 & 2 & 3 & 4 & \\
\hline Organic carbon, OC & 0.86 & 0.29 & 0.12 & 0.28 & 0.92 \\
\hline Total nitrogen, TN & 0.86 & 0.21 & 0.04 & 0.36 & 0.92 \\
\hline Earthworm per $\mathrm{m}^{2}, \mathrm{EW}$ & 0.79 & 0.27 & 0.28 & 0.23 & 0.82 \\
\hline Porosity & 0.74 & 0.38 & 0.40 & 0.30 & 0.94 \\
\hline Zinc, $\mathrm{Zn}$ & 0.70 & 0.46 & 0.31 & 0.16 & 0.82 \\
\hline Water-holding capacity, WHC & 0.69 & 0.47 & 0.47 & 0.20 & 0.96 \\
\hline Available phosphorus, Pav & 0.69 & 0.34 & 0.31 & 0.11 & 0.71 \\
\hline A-horizon depth, AHD & 0.64 & 0.37 & 0.48 & 0.41 & 0.94 \\
\hline Soil aggregate stability, SAS & 0.60 & 0.45 & 0.52 & 0.33 & 0.94 \\
\hline Exchangeable potassium, $\mathrm{K}$ & 0.27 & 0.83 & 0.28 & 0.17 & 0.86 \\
\hline Cation exchangeable capacity, CEC & 0.42 & 0.76 & 0.51 & 0.29 & 0.95 \\
\hline Exchangeable calcium, Ca & 0.41 & 0.72 & 0.40 & 0.28 & 0.93 \\
\hline Total phosphorous, TP & 0.45 & 0.70 & 0.38 & 0.11 & 0.85 \\
\hline Exchangeable magnesium, Mg & 0.53 & 0.68 & 0.38 & 0.24 & 0.94 \\
\hline Sum base forming cations, SBF & 0.45 & 0.63 & 0.40 & 0.26 & 0.97 \\
\hline Silt & 0.19 & 0.39 & 0.84 & 0.04 & 0.90 \\
\hline Dry bulk density, DBD & -0.40 & -0.38 & -0.78 & -0.30 & 0.94 \\
\hline $\mathrm{pH}$ & 0.22 & 0.26 & 0.74 & 0.26 & 0.82 \\
\hline Sand & -0.34 & -0.36 & -0.67 & -0.30 & 0.91 \\
\hline EC & 0.38 & 0.44 & 0.55 & -0.03 & 0.64 \\
\hline Exchangeable sodium, $\mathrm{Na}$ & -0.18 & -0.18 & 0.01 & -0.57 & 0.82 \\
\hline Iron, $\mathrm{Fe}$ & -0.30 & -0.08 & -0.13 & 0.86 & 0.85 \\
\hline Exchangeable sodium percentage, ESP & -0.17 & -0.25 & -0.49 & -0.59 & 0.97 \\
\hline Clay & 0.51 & 0.13 & 0.21 & 0.63 & 0.72 \\
\hline Eigenvalue & 7.26 & 5.16 & 4.79 & 3.82 & - \\
\hline Variance (\%) & 30.26 & 21.51 & 19.96 & 15.90 & - \\
\hline Cumulative variance (\%) & 30.26 & 51.77 & 71.73 & 87.63 & - \\
\hline
\end{tabular}

Boldface eigenvector values correspond to the PCs highly weighted variables examined for the index

Bold-italic factors correspond to the indicators retained in the SQ index. The weight of the variables included in the index was decided using the variance of each factor.

$\mathrm{PCA}-\mathrm{SQI}=0.303 \mathrm{OC}+0.0303 \mathrm{TN}+0.215 \mathrm{CEC}+0.215 \mathrm{TP}+0.200 \mathrm{silt}+0.200 \mathrm{DBD}+0.159 \mathrm{Fe}$.

Normalized PCA-SQI $=(0.303 \mathrm{OC}+0.0303 \mathrm{TN}+0.215 \mathrm{CEC}+0.215 \mathrm{TP}+0.200$ silt $+0.200 \mathrm{DBD}+0.159 \mathrm{Fe}) /(1.595)=0.190 \mathrm{OC}+0.190 \mathrm{TN}+0.135 \mathrm{CEC}+$ $0.135 \mathrm{TP}+0.125 \mathrm{silt}+0.125 \mathrm{DBD}+0.100 \mathrm{Fe}$.

by LS3 and LS7 is more advantageous in maintaining SQ than the other LUSMS in the catchment.

3.2.2. PCA Based Soil Quality Indices (PCA-SQI). For both PCA and EO databases, NLSF methods resulted in higher SQI values than LSF (Tables 5 and 6). In contrast to unscreenedSQI values, PCA-SQI values derived from PCA selected datasets were higher than those derived using EO datasets. Once again, the $\mathrm{I}^{\mathrm{N}}$ and $\mathrm{II}^{\mathrm{L}}$ indexing methods resulted in the highest PCA-SQI values for both data selection methods (Tables 5 and 6). Among the LUSMS, the PCA-SQI value for LS1 was significantly higher $(P=0.05)$ than the other land uses although it has been just slightly better than LS2 and LS3. LS8 had the lowest PCA-SQI value followed closely by LS5 and LS6 (Tables 5 and 6). Soil degradation based on PCASQI differences between each LUSMS and the LS1 reference averaged $-6,-21,-23,-24,-34,-36$, and $-59 \%$ for LS2, LS3,
LS7, LS4, LS5, LS6, and LS8, respectively, when computed using average values for PCA and EO derived datasets.

3.3. Dataset Selection, Scoring, and Indexing Methods Comparison. Using NLSF, PCA-SQI values were greater than unscreened-SQI values but with LSF methods unscreenedSQI values were higher. Comparing MDS selection methods, unscreened-SQI values derived using an EO dataset were higher for both LSF and NLSF methods (Tables 5 and 6 ). The $\mathrm{II}^{\mathrm{L}}$ and $\mathrm{I}^{\mathrm{N}}$ scoring methods resulted in higher SQI values than the other methods. Overall, for almost all LUSMS, NLSF values were generally greater than LSF values. Mean SQI values using PCA selected datasets ranged from 0.458 (LS8) to 0.932 (LS1) (Table 5). The overall average using EO selected datasets ranged from 0.406 (LS8) to 0.874 (LS1) (Table 6). This implies that mean SQI values calculated from both indexing methods using EO datasets resulted in lower index values than with 
TABLE 5: Soil quality indices developed using a PCA selected dataset to compare eight LUSMS in the Mai-Negus catchment of northern Ethiopia.

\begin{tabular}{|c|c|c|c|c|c|c|c|c|c|c|c|}
\hline \multirow{3}{*}{ LUSMS } & \multicolumn{5}{|c|}{ Unscreened SQI } & \multicolumn{5}{|c|}{ PCA-SQI } & \multirow{3}{*}{ Mean $^{\mathrm{b}}$} \\
\hline & \multicolumn{3}{|c|}{$\mathrm{LSF}^{\mathrm{a}}$} & \multicolumn{2}{|c|}{$\mathrm{NLSF}^{\mathrm{a}}$} & \multicolumn{3}{|c|}{ LSF } & \multicolumn{2}{|c|}{ NLSF } & \\
\hline & $\mathrm{I}^{\mathrm{L}}$ & $\mathrm{II}^{\mathrm{L}}$ & $\mathrm{III}^{\mathrm{L}}$ & $\mathrm{I}^{\mathrm{N}}$ & $\mathrm{II}^{\mathrm{N}}$ & $\mathrm{I}^{\mathrm{L}}$ & $\mathrm{II}^{\mathrm{L}}$ & III $^{\mathrm{L}}$ & $\mathrm{I}^{\mathrm{N}}$ & $\mathrm{II}^{\mathrm{N}}$ & \\
\hline LS1 & $0.913^{\mathrm{a}}$ & $0.941^{\mathrm{a}}$ & $0.899^{\mathrm{a}}$ & $0.956^{\mathrm{a}}$ & $0.953^{\mathrm{a}}$ & $0.913^{\mathrm{a}}$ & $0.925^{\mathrm{a}}$ & $0.881^{\mathrm{a}}$ & $0.973^{\mathrm{a}}$ & $0.964^{\mathrm{a}}$ & $0.932^{\mathrm{a}}$ \\
\hline LS2 & $0.823^{\mathrm{a}}$ & $0.843^{\mathrm{a}}$ & $0.793^{\mathrm{b}}$ & $0.920^{\mathrm{a}}$ & $0.916^{\mathrm{a}}$ & $0.826^{\mathrm{b}}$ & $0.845^{\mathrm{a}}$ & $0.795^{\mathrm{b}}$ & $0.928^{\mathrm{a}}$ & $0.921^{\mathrm{a}}$ & $0.861^{\mathrm{a}}$ \\
\hline LS3 & $0.621^{\mathrm{bc}}$ & $0.659^{\mathrm{b}}$ & $0.626^{\mathrm{c}}$ & $0.747^{\text {bcd }}$ & $0.741^{\mathrm{bcd}}$ & $0.619^{c}$ & $0.658^{\mathrm{b}}$ & $0.593^{\mathrm{c}}$ & $0.773^{b c}$ & $0.754^{\mathrm{bc}}$ & $0.679^{b}$ \\
\hline LS4 & $0.648^{\mathrm{b}}$ & $0.673^{\mathrm{b}}$ & $0.627^{\mathrm{c}}$ & $0.780^{\mathrm{bc}}$ & $0.777^{\mathrm{bc}}$ & $0.618^{\mathrm{c}}$ & $0.608^{\mathrm{bc}}$ & $0.587^{\mathrm{c}}$ & $0.774^{\mathrm{bc}}$ & $0.772^{\mathrm{bc}}$ & $0.686^{\mathrm{b}}$ \\
\hline LS5 & $0.539^{\mathrm{cd}}$ & $0.582^{b c}$ & $0.522^{\mathrm{d}}$ & $0.689^{\mathrm{cd}}$ & $0.686^{\mathrm{cd}}$ & $0.484^{\mathrm{d}}$ & $0.535^{\mathrm{cd}}$ & $0.470^{\mathrm{d}}$ & $0.696^{\mathrm{cd}}$ & $0.692^{\mathrm{cd}}$ & $0.589^{c}$ \\
\hline LS6 & $0.506^{\mathrm{d}}$ & $0.532^{\text {cd }}$ & $0.510^{\mathrm{d}}$ & $0.655^{\mathrm{de}}$ & $0.652^{\mathrm{de}}$ & $0.463^{\mathrm{d}}$ & $0.514^{\mathrm{d}}$ & $0.453^{\mathrm{d}}$ & $0.656^{\mathrm{d}}$ & $0.653^{\mathrm{d}}$ & $0.559^{c}$ \\
\hline LS7 & $0.639^{\mathrm{b}}$ & $0.676^{\mathrm{b}}$ & $0.660^{c}$ & $0.787^{\mathrm{b}}$ & $0.784^{\mathrm{b}}$ & $0.597^{\mathfrak{c}}$ & $0.638^{\mathrm{b}}$ & $0.591^{\mathrm{c}}$ & $0.791^{b}$ & $0.781^{\mathrm{b}}$ & $0.694^{b}$ \\
\hline LS8 & $0.410^{\mathrm{e}}$ & $0.475^{\mathrm{d}}$ & $0.405^{\mathrm{e}}$ & $0.562^{\mathrm{e}}$ & $0.559^{\mathrm{e}}$ & $0.347^{\mathrm{e}}$ & $0.418^{\mathrm{e}}$ & $0.341^{\mathrm{e}}$ & $0.513^{\mathrm{e}}$ & $0.546^{\mathrm{e}}$ & $0.458^{\mathrm{d}}$ \\
\hline mean & 0.637 & 0.672 & 0.630 & 0.762 & 0.759 & 0.609 & 0.642 & 0.589 & 0.763 & 0.760 & 0.682 \\
\hline $\operatorname{LSD}(P=0.05)$ & 0.095 & 0.099 & 0.091 & 0.097 & 0.096 & 0.086 & 0.082 & 0.076 & 0.089 & 0.089 & 0.083 \\
\hline
\end{tabular}

Means followed by different letters in the same column are significantly different at $P=0.05$; LSD: least significance difference.

${ }^{a}$ Details of LSF and NLSF descriptions can be found in Section 2.4 (Step 2).

${ }^{\mathrm{b}}$ This shows overall mean of the different scoring and indexing methods across the columns for the same LUSMS as tested statistically.

LSF: linear scoring function; NLSF: nonlinear scoring function; $\mathrm{I}^{\mathrm{L}}$ : Liebig method LSF; $\mathrm{II}^{\mathrm{L}}$ : Homothetic transformation method of LSF; III ${ }^{\mathrm{L}}$ : Glover method LSF; $I^{N}$ : CurveExpert method NLSF; II ${ }^{\mathrm{N}}$ : Glover method NLSF; LUSMS: land use and soil management systems; SQI: soil quality index; PCA: principal component analysis; LS1: natural forest (reference); LS2: plantation of protected area; LS3: pasture land system; LS4: teff-faba bean rotation; LS5: teff-barley/wheat rotation; LS6: teff-monocropping; LS7: Maize monocropping; LS8: uncultivated-marginal land soil system.

TABLE 6: Soil quality indices developed using an EO selected dataset to compare eight LUSMS in the Mai-Negus catchment of northern Ethiopia.

\begin{tabular}{|c|c|c|c|c|c|c|c|c|c|c|c|}
\hline \multirow{3}{*}{ LUSMS } & \multicolumn{5}{|c|}{ Unscreened SQI } & \multicolumn{5}{|c|}{ PCA-SQI } & \multirow{3}{*}{ Mean $^{\mathrm{b}}$} \\
\hline & \multicolumn{3}{|c|}{$\mathrm{LSF}^{\mathrm{a}}$} & \multicolumn{2}{|c|}{$\mathrm{NLSF}^{\mathrm{a}}$} & \multicolumn{3}{|c|}{ LSF } & \multicolumn{2}{|c|}{ NLSF } & \\
\hline & $\mathrm{I}^{\mathrm{L}}$ & $\mathrm{II}^{\mathrm{L}}$ & $\mathrm{III}^{\mathrm{L}}$ & $\mathrm{I}^{\mathrm{N}}$ & $\mathrm{II}^{\mathrm{N}}$ & $\mathrm{I}^{\mathrm{L}}$ & $\mathrm{II}^{\mathrm{L}}$ & $\mathrm{III}^{\mathrm{L}}$ & $\mathrm{I}^{\mathrm{N}}$ & $\mathrm{II}^{\mathrm{N}}$ & \\
\hline LS1 & $0.937^{\mathrm{a}}$ & $0.943^{\mathrm{a}}$ & $0.925^{\mathrm{a}}$ & $0.966^{\mathrm{a}}$ & $0.964^{\mathrm{a}}$ & $0.796^{\mathrm{a}}$ & $0.799^{\mathrm{a}}$ & $0.779^{\mathrm{a}}$ & $0.818^{\mathrm{a}}$ & $0.816^{\mathrm{a}}$ & $0.874^{\mathrm{a}}$ \\
\hline LS2 & $0.828^{\mathrm{b}}$ & $0.831^{\mathrm{b}}$ & $0.786^{\mathrm{b}}$ & $0.920^{\mathrm{a}}$ & $0.918^{\mathrm{a}}$ & $0.724^{\mathrm{b}}$ & $0.723^{\mathrm{b}}$ & $0.690^{\mathrm{b}}$ & $0.783^{\mathrm{a}}$ & $0.781^{\mathrm{a}}$ & $0.799^{\mathrm{b}}$ \\
\hline LS3 & $0.707^{\mathrm{c}}$ & $0.720^{c}$ & $0.673^{c}$ & $0.830^{\mathrm{b}}$ & $0.828^{\mathrm{b}}$ & $0.612^{c}$ & $0.622^{\mathrm{c}}$ & $0.584^{\mathrm{c}}$ & $0.708^{\mathrm{b}}$ & $0.666^{\mathrm{b}}$ & $0.695^{\mathrm{c}}$ \\
\hline LS4 & $0.652^{c}$ & $0.662^{\mathrm{c}}$ & $0.610^{\mathrm{c}}$ & $0.775^{\mathrm{b}}$ & $0.773^{\mathrm{b}}$ & $0.556^{\mathrm{d}}$ & $0.565^{\mathrm{d}}$ & $0.522^{\mathrm{d}}$ & $0.651^{\mathrm{c}}$ & $0.650^{\mathrm{b}}$ & $0.642^{\mathrm{d}}$ \\
\hline LS5 & $0.529^{\mathrm{d}}$ & $0.552^{\mathrm{d}}$ & $0.491^{\mathrm{d}}$ & $0.658^{c}$ & $0.656^{\mathrm{c}}$ & $0.448^{\mathrm{e}}$ & $0.468^{\mathrm{e}}$ & $0.417^{\mathrm{e}}$ & $0.548^{\mathrm{d}}$ & $0.546^{\mathrm{c}}$ & $0.531^{\mathrm{e}}$ \\
\hline LS6 & $0.501^{\mathrm{d}}$ & $0.526^{\mathrm{d}}$ & $0.461^{\mathrm{d}}$ & $0.621^{\mathrm{c}}$ & $0.619^{c}$ & $0.428^{\mathrm{e}}$ & $0.450^{\mathrm{e}}$ & $0.397^{\mathrm{e}}$ & $0.497^{\mathrm{e}}$ & $0.517^{\mathrm{c}}$ & $0.502^{\mathrm{e}}$ \\
\hline LS7 & $0.657^{\mathrm{c}}$ & $0.670^{\mathrm{c}}$ & $0.622^{c}$ & $0.773^{\mathrm{b}}$ & $0.771^{\mathrm{c}}$ & $0.545^{\mathrm{d}}$ & $0.558^{\mathrm{d}}$ & $0.514^{\mathrm{d}}$ & $0.653^{c}$ & $0.651^{b}$ & $0.641^{\mathrm{d}}$ \\
\hline LS8 & $0.397^{\mathrm{e}}$ & $0.434^{\mathrm{e}}$ & $0.361^{\mathrm{e}}$ & $0.511^{\mathrm{d}}$ & $0.509^{\mathrm{d}}$ & $0.335^{\mathrm{f}}$ & $0.369^{\mathrm{f}}$ & $0.307^{\mathrm{f}}$ & $0.420^{\mathrm{f}}$ & $0.418^{\mathrm{d}}$ & $0.406^{\mathrm{f}}$ \\
\hline mean & 0.651 & 0.667 & 0.616 & 0.756 & 0.754 & 0.556 & 0.569 & 0.526 & 0.635 & 0.631 & 0.636 \\
\hline $\operatorname{LSD}(P=0.05)$ & 0.066 & 0.059 & 0.067 & 0.060 & 0.060 & 0.044 & 0.038 & 0.042 & 0.042 & 0.051 & 0.048 \\
\hline
\end{tabular}

Means followed by different letters in the same rows are significantly different at $P=0.05$; LSD: least significance difference.

${ }^{a}$ Details of LSF and NLSF description can be found in Section 2.4 (Step 2).

${ }^{b}$ This shows the overall mean of the different scoring and indexing methods across the columns for the same LUSMS tested statistically.

Explanations of abbreviations are similar to footnotes under Table 5.

PCA selected datasets. Therefore, this study concludes that adopting the PCA dataset selection method is the best for evaluating the soil degradation status of LUSMS in northern Ethiopia and under similar environmental conditions. The use of a PCA dataset selection method also minimizes any disciplinary bias that may be associated with the EO selection method.

3.4. Evaluation of Indexing Methods. The unscreened-SQI values varied from 0.410 to 0.933 and 0.397 to 0.954 for the PCA and EO dataset selection methods, respectively. Likewise, PCA-SQI values ranged from 0.347 to 0.934 and 0.335 to 0.801 for the two dataset selection methods, respectively (Table 7). A sensitivity analysis showed that both indexing and dataset selection methods influenced the SQI values for the various LUSMS throughout the catchment (Table 7). It also confirmed that indexing, scoring, and MDS selection can be used to evaluate soil degradation among LUSMS in the Mai-Negus catchment of northern Ethiopia. However, the sensitivity analyses do not agree with findings reported by Masto et al. [11] and Andrews et al. [53] who favored NLSF over LSF. One reason for this difference is that the previous reports were based on single scoring functions from LSF and NLSF methods and their sensitivity was not evaluated. 
TABLE 7: Dataset selection, scoring function, and indexing method comparisons for eight LUSMS in the Mai-Negus catchment of northern Ethiopia.

\begin{tabular}{|c|c|c|c|c|c|c|c|c|c|c|}
\hline \multirow{3}{*}{ SQ indexing method } & \multicolumn{6}{|c|}{ Linear scoring function } & \multicolumn{4}{|c|}{ Nonlinear scoring function } \\
\hline & \multicolumn{2}{|l|}{$\mathrm{I}^{\mathrm{L}}$} & \multicolumn{2}{|l|}{$\mathrm{II}^{\mathrm{L}}$} & \multicolumn{2}{|l|}{$\mathrm{III}^{\mathrm{L}}$} & \multicolumn{2}{|l|}{$\mathrm{I}^{\mathrm{N}}$} & \multicolumn{2}{|l|}{$\mathrm{II}^{\mathrm{N}}$} \\
\hline & Range & $S$ & Range & $S$ & Range & $S$ & Range & $S$ & Range & $S$ \\
\hline Unscreened-SQI ${ }^{\mathrm{a}}$ & $0.410-0.913$ & 2.227 & $0.475-0.941$ & 1.981 & $0.405-0.899$ & 2.220 & $0.562-0.956$ & 1.701 & $0.559-0.953$ & 1.705 \\
\hline PCA-SQI ${ }^{\mathrm{a}}$ & $0.347-0.913$ & 2.631 & $0.418-0.923$ & 2.208 & $0.341-0.881$ & 2.584 & $0.513-0.973$ & 1.898 & $0.546-0.964$ & 1.766 \\
\hline Unscreened-SQI $^{\mathrm{b}}$ & $0.397-0.937$ & 2.360 & $0.434-0.943$ & 2.173 & $0.361-0.925$ & 2.562 & $0.511-0.966$ & 1.890 & $0.508-0.964$ & 1.897 \\
\hline PCA-SQI $^{\mathrm{b}}$ & $0.335-0.796$ & 2.376 & $0.369-0.799$ & 2.165 & $0.307-0.779$ & 2.537 & $0.420-0.818$ & 1.952 & $0.418-0.816$ & 1.948 \\
\hline Mean & - & 2.399 & - & 2.132 & - & 2.476 & - & 1.859 & - & 1.830 \\
\hline
\end{tabular}

a denotes minimum dataset chosen using principal component analyses (PCA).

${ }^{\mathrm{b}}$ denotes minimum dataset chosen by expert opinion (EO).

$\mathrm{I}^{\mathrm{L}}$ : Liebig method LSF; II ${ }^{\mathrm{L}}$ : Homothetic transformation method of LSF; III ${ }^{\mathrm{L}}$ : Glover method LSF; $\mathrm{I}^{\mathrm{N}}$ : CurveExpert method NLSF; $\mathrm{II}^{\mathrm{N}}$ : Glover method NLSF; S: Sensitivity analysis; LSF: linear scoring function; NLSF: nonlinear scoring function.

Also, many of the LSF and NLSF approaches evaluated in this project were not addressed at the same time and place in the previous studies.

3.5. Synthesis of Dataset Selection, Scoring, and SQ Indexing Methods. Dataset selection methods (PCA versus EO), scoring functions, and indexing approaches all influenced the SQI values used to compare LUSMS in northern Ethiopia (Tables 5, 6 and 7). This study results were consistent with previous studies that also showed these factors contributed to variability in SQI values [11, 16, 34, 35]. Arguments favoring EO method for selection of a MDS stress its focus on sustainable management goals $[11,36,45]$, but many researchers have also relied on statistical techniques such as PCA (e.g., $[11,16,53])$. This study confirmed PCA selection could reduce expert biases as compared to an EO method. Andrews et al. [16] reported that EO and PCA dataset selection methods produced almost similar SQI values, but PCA-SQI values using PCA and NLSF methods in this study were higher. This was not true for unscreened-SQI which was obtained by summing scores for individual indicators.

Many studies have shown that NLSF resulted in higher SQI values than LSF $[11,16]$, but a sensitivity analysis showed that the $\mathrm{I}^{\mathrm{L}}$ method explained variation better than the NLSF method for both indexing methods. This was followed by another LSF method denoted as III ${ }^{\mathrm{L}}$. Several strategies for integrating scored indicators values into an overall SQI have been proposed, but no approach has received universally acceptance [11].

SQI values were segregated into physical, chemical, and biological components (Figure 3) to show the component effects on SQ and thus soil degradation within each LUSMS in the catchment. The individual factors also permit comparisons among the scoring methods that help illustrate differences among them. Finally, although such comparisons are interesting, they are not adequate for assessing SQ effects of LUSMS because numerous interactions also contribute to the overall SQI values $[13,15]$. This is also a major reason that use of a single SQ indicator regardless of how its scored or interpreted is not suitable for comparing overall soil degradation dynamics among LUSMS.
Several studies have shown that agroforestry can be a viable option for restoration of degraded land as it improves soil indicators such as organic matter, nitrogen cycling, soil structure, and biological activity [54-56]. Others have added that extensive rooting systems and protective canopies of the Leucaena leeucocephala and Sesbania sesban trees can protect the soil from erosion and create favorable conditions for plant and microbial growth $[56,57]$. Litter-fall and fine roots decomposition both contribute to these processes. This study shows higher SQI value for LS1 and LS2 because of better vegetation cover (natural and plantation), which is consistent with previous reports [54-57]. Overall, this study confirmed that SQI values can be developed and used as tools for early identification of land degradation particularly the soil component. They can also be used to support decision making processes with regard to sustainable soil management planning in the context of different LUSMS at catchment scale.

\section{Conclusion}

This study demonstrated that natural forest land systems (LS1) have relatively good soil quality (SQ), whereas uncultivated marginal land systems (LS8) have a seriously degraded soil within the Mai-Negus catchment of northern Ethiopia. Areas being managed in a teff-barley/wheat rotation land system (LS5) and teff monocropping (LS6) also had not reasonably good SQ. SQI values for LS8 and LS6 provided an early warning regarding the severity of soil degradation since more than $50 \%$ of the original soil is degraded when compared to LS1 (reference soil). The PCA-SQI method resulted in a higher SQI value than the unscreened-SQI for NLSF when datasets were selected using a PCA method. However, the reverse was true for the datasets selected using an EO method. The NLSF methods resulted in higher SQI values than LSF methods for all LUSMS regardless of the SQ indexing method. Among NLSF, the CurveExpert method $\left(\mathrm{I}^{\mathrm{N}}\right)$ showed the highest SQI for the dataset selected by the PCA method. However, a sensitivity analysis indicated that PCA-SQI with the LSF (denoted as I $\mathrm{I}^{\mathrm{L}}$ or the "Liebig method") and a PCA derived dataset had the highest values. The lowest 


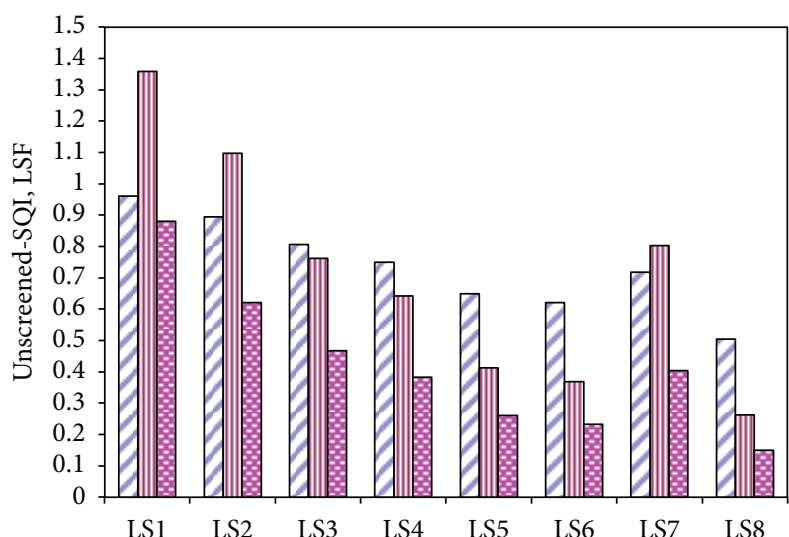

(a)

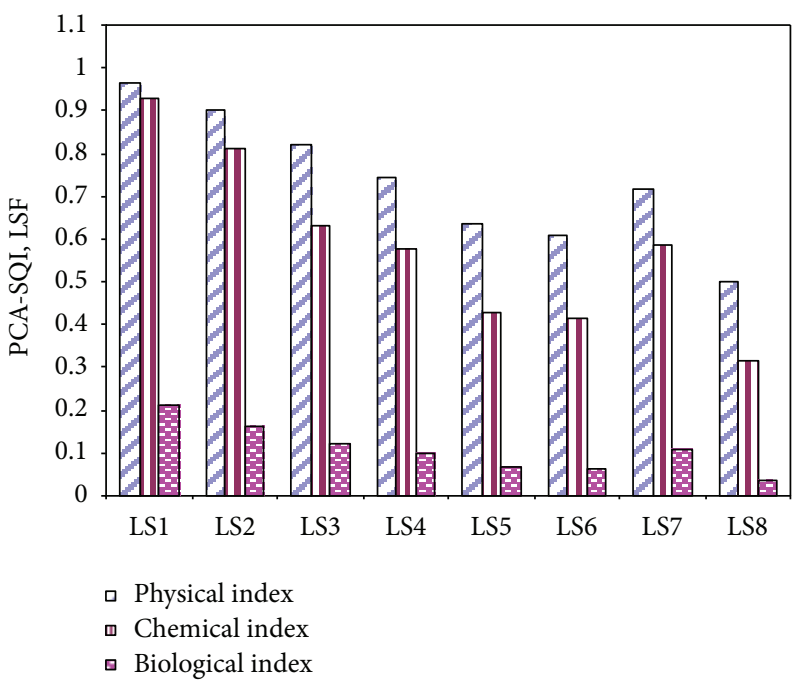

(c)

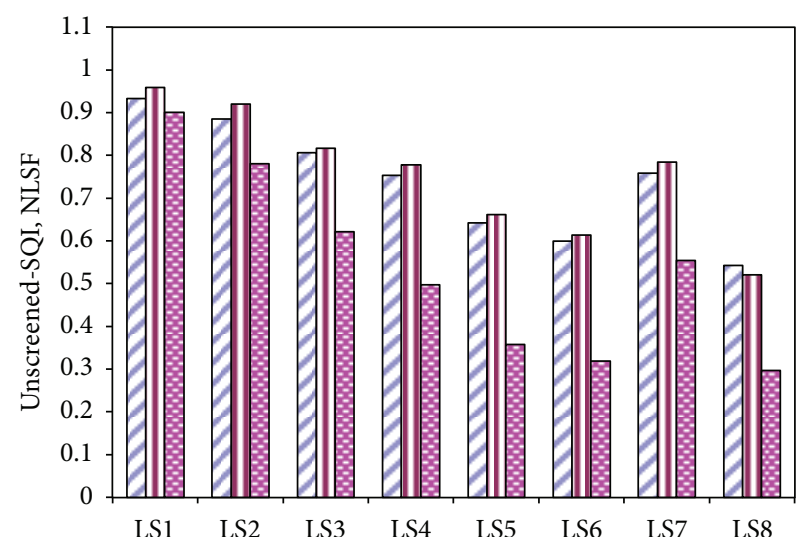

(b)

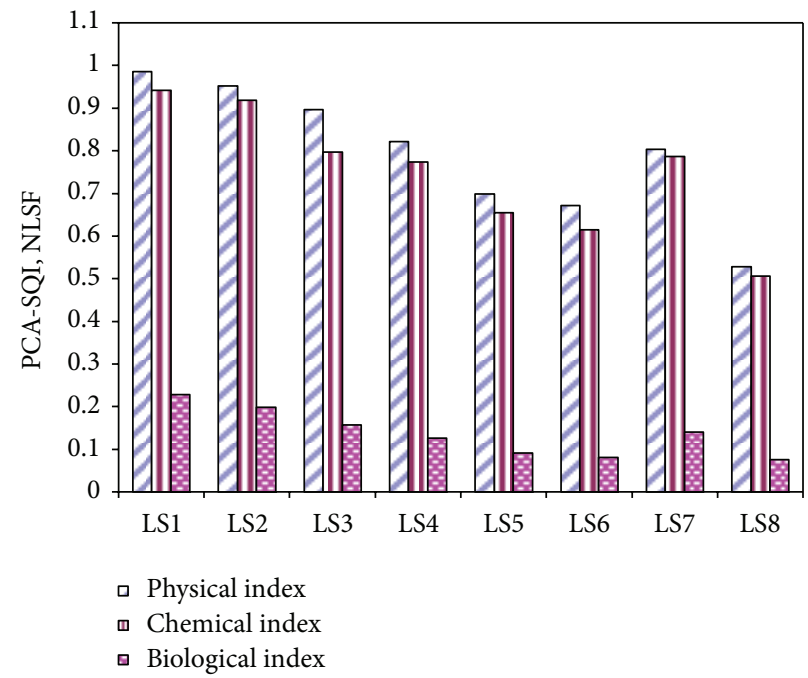

(d)

FIGURE 3: LUSMS effects on mean physical, chemical, and biological soil quality indicator scores for different indexing methods within the Mai-Negus catchment of northern Ethiopia.

sensitivity values were associated with an unscreened-SQI using NLSF method denoted as $\mathrm{II}^{\mathrm{N}}$ (Glover method NLSF) using PCA derived datasets. This study also indicated that the PCA-SQI method with a PCA selected dataset and a LSF designated as $\mathrm{I}^{\mathrm{L}}$ was the most sensitive for assessing differences among the eight LUSMS in northern Ethiopia. Based on this study result, the researcher concludes that use of relevant datasets, scoring functions, and indexing methods are all important factors influencing SQI values within the eight LUSMS. Also, for improving degraded soils and maintaining SQ, appropriate interventions within the various LUSMS should be identified, prioritized, and monitored using SQI values as decision aids.

\section{Conflict of Interests}

The author does not have a direct financial relation with the commercial identity mentioned in this paper that might lead to a conflict of interests.

\section{Acknowledgments}

The author gratefully acknowledges the financial support by DAAD/GIZ (Germany) through the Center for Development Research (ZEF), University of Bonn (Germany), and field work supported by Aksum University (Ethiopia). The author also highly appreciates the cooperation of the participant farmers and assistance offered by the local administration and extension agents during the field work. The author is also grateful to the anonymous reviewers for their comments which helped in improving this paper.

\section{References}

[1] H. Eswaran, R. Lal, and P. F. Reich, "Land degradation: an overview," in Response to Land Degradation, E. M. Bridges, I. D. Hannam, L. R. Oldeman, F. W. T. Penning De Vries, J. S. Scherr, and S. Sombatpanit, Eds., pp. 20-35, Science Publishers, Enfield, NH, USA, 2001. 
[2] G. Girmay, B. R. Singh, H. Mitiku, T. Borresen, and R. Lal, "Carbon stocks in Ethiopian soils in relation to land use and soil management," Land Degradation and Development, vol. 19, no. 4, pp. 351-367, 2008.

[3] R. Lal, "Soil erosion problems on alfisols in Western Nigeria, VI. Effects of erosion on experimental plots," Geoderma, vol. 25, no. 3-4, pp. 215-230, 1981.

[4] R. Lal, T. M. Sobecki, T. Iivari, and J. M. Kimble, Soil Degradation in the United States: Extent, Severity and Trends, CRC Press, Boca Raton, Fla, USA, 2003.

[5] M. A. Denboba, Forest conversion-soil degradation-farmers' perception nexus: implications for sustainable land use in the Southwest of Ethiopia [Ph.D. thesis], University of Bonn, Bonn, Germany, 2005.

[6] J. W. Doran, "Soil health and global sustainability: translating science into practice," Agriculture, Ecosystems and Environment, vol. 88, no. 2, pp. 119-127, 2002.

[7] H. Hurni, K. Tato, and G. Zeleke, "The implications of changes in population, land use, and land management for surface runoff in the Upper Nile Basin Area of Ethiopia," Mountain Research and Development, vol. 25, no. 2, pp. 147-154, 2005.

[8] A. Glanz, Saving Our Soil: Solutions for Sustaining Earth's Vital Resource, Johnson Books, Boulder, Colo, USA, 1995.

[9] J. F. Parr, R. I. Papendick, S. B. Hornick, and R. E. Meyer, "Soil quality: attributes and relationship to alternative and sustainable agriculture," American Journal of Alternative Agriculture, vol. 7, no. 1-2, pp. 5-11, 1992.

[10] M. R. Carter, "Soil quality for sustainable land management: organic matter and aggregation interactions that maintain soil functions," Agronomy Journal, vol. 94, no. 1, pp. 38-47, 2002.

[11] R. E. Masto, P. K. Chhonkar, D. Singh, and A. K. Patra, "Alternative soil quality indices for evaluating the effect of intensive cropping, fertilisation and manuring for 31 years in the semi-arid soils of India," Environmental Monitoring and Assessment, vol. 136, no. 1-3, pp. 419-435, 2008.

[12] Z. Sakbaeva, V. Acosta-Martinez, J. Moore-Kucera, W. Hudnall, and K. Nuridin, "Interactions of soil order and land use management on soil properties in the Kukart watershed, Kyrgyzstan," Applied and Environmental Soil Science, vol. 2012, Article ID 130941, 11 pages, 2012.

[13] S. S. Andrews, D. L. Karlen, and C. A. Cambardella, "The soil management assessment framework: a quantitative soil quality evaluation method," Soil Science Society of America Journal, vol. 68, no. 6, pp. 1945-1962, 2004.

[14] W. J. Elliot, D. P. Dumroese, and P. R. Robichaud, "The effects of forest management on erosion and soil productivity," in Soil Quality and Soil Erosion, R. Lal, Ed., pp. 195-209, CRC Press, Boca Raton, Fla, USA, 1999.

[15] M. C. Amacher, K. P. O’Neill, and C. H. Perry, "Soil vital signs: a new soil quality index (SQI) for assessing forest soil health," Research Paper of USDA, Forest Service, Rocky Mountain Research Station, 2007.

[16] S. S. Andrews, D. L. Karlen, and J. P. Mitchell, "A comparison of soil quality indexing methods for vegetable production systems in Northern California," Agriculture, Ecosystems and Environment, vol. 90, no. 1, pp. 25-45, 2002.

[17] R. F. Harris, D. L. Karlen, and D. J. Mulla, "A conceptual framework for assessment and management of soil quality and health," in Methods for Assessing Soil Quality, J. W. Doran and A. J. Jones, Eds., vol. 49, pp. 61-82, Soil Science Society of America, Madison, Wis, USA, 1996.
[18] S. S. Andrews and C. R. Carroll, "Designing a soil quality assessment tool for sustainable agroecosystem management," Ecological Applications, vol. 11, no. 6, pp. 1573-1585, 2001.

[19] B. K. Gugino, O. J. Idowu, R. R. Schindelbeck et al., Cornell Soil Health Assessment Training Manual, Cornell University, Geneva, NY, USA, 2nd edition, 2009.

[20] Food and Agriculture Organization of the United Nations, The Soil and Terrain Database for Northeastern Africa (CDROM), FAO, Rome, Italy, 1998.

[21] J. A. Burger and D. L. Kelting, "Soil quality monitoring for assessing sustainable forest management," in The Contribution of Soil Science to the Development and Implementation of Criteria and Indicators of Sustainable Forest Management, J. M. Gigham, Ed., vol. 53, pp. 17-45, Soil Science Society of America, Madison, Wis, USA, 1998.

[22] G. W. Gee and J. W. Bauder, "Particle-size analysis," in Methods of Soil Analysis, A. Klute, Ed., Part 1, pp. 383-411, America Society of Agronomy, Soil Science Society of America, Madison, Wis, USA, 1986.

[23] G. R. Blake and K. H. Hartge, "Bulk density," in Methods of Soil Analysis, A. Klute, Ed., Agronomy Monograph 9, Part 1, pp. 363375, America Society of Agronomy, Madison, Wis, USA, 1986.

[24] The Nature and Properties of Soils, Prentice-Hall, Upper Saddle River, NJ, USA, 13th edition, 2002, edited by N.C. Brady and R.R. Weil.

[25] M. H. Beare and R. Russell Bruce, "A comparison of methods for measuring water-stable aggregates: implications for determining environmental effects on soil structure," Geoderma, vol. 56, pp. 87-104, 1993.

[26] T. C. Baruah and H. P. Barthakur, A Text Book of Soil Analysis, Vikas Publishing House, New Delhi, India, 1999.

[27] G. W. Thomas, "Soil pH and soil acidity," in Methods of Soil Analysis: Chemical Methods, D. L. Sparks, Ed., part 3, pp. 475490, Soil Science Society of America, Madison, Wis, USA, 1996.

[28] J. M. Bremmer and C. S. Mulvaney, "Nitrogen total," in Method of Soil Analysis, Part 2. Chemical and Microbiological Properties, A. L. Page, Ed., Agronomy Monograph 9, pp. 595-624, America Society of Agronomy, Madison, Wis, USA, 1982.

[29] S. R. Olsen and L. E. Sommers, "Phosphorus," in Method of Soil Analysis: Chemical and Microbiological Properties, A. L. Page, Ed., Agronomy Monograph 9, part 2, pp. 403-430, America Society of Agronomy, Madison, Wis, USA, 1982.

[30] J. M. Anderson and J. S. I. Ingram, Tropical Soil Biology and Fertility, A Handbook of Methods, CAB International, Wallingford, UK, 1993.

[31] J. D. Rhoades, "Cation exchange capacity," in Methods of Soil Analysis, A. L. Page, R. H. Miller, and D. R. Keeney, Eds., Agronomy Monograph 9, part 2, pp. 149-157, America Society of Agronomy, Madison, Wis, USA, 1982.

[32] M. S. Coyne and J. A. Thompson, Math for Soil Scientists, Thomson Delmar Learning, Clifton Park, NY, USA, 2006.

[33] S. S. Andrews, Sustainable agriculture alternatives: ecological and managerial implications of poultry litter management alternatives applied for agronomic soils [Ph.D. dissertation], University of Georgia, Athens, Ga, USA, 1998.

[34] J. W. Doran and T. B. Parkin, "Defining and assessing soil quality," in Defining Soil Quality for a Sustainable Environment, J. W. Doran, D. G. Coleman, D. F. Bezddick, and B. A. Stewart, Eds., pp. 3-22, Soil Science Society of America, Madison, Wis, USA, 1994. 
[35] J. W. Doran and T. B. Parkin, "Quantitative indicators of soil quality: a minimum data set," in Methods for Assessing Soil Quality, J. W. Doran and J. Jones, Eds., pp. 25-38, Soil Science Society of America, Madison, Wis, USA, 1996.

[36] W. E. Larson and F. J. Pierce, "The dynamics of soil quality as a measure of sustainable management," in Defining Soil Quality for Sustainable Environment, J. W. Doran, D. G. Coleman, D. F. Bezddick, and B. A. Stewart, Eds., pp. 37-52, Soil Science Society of America, Madison, Wis, USA, 1994.

[37] M. A. Liebig, G. Varvel, and J. Doran, "A simple performancebased index for assessing multiple agroecosystem functions," Agronomy Journal, vol. 93, no. 2, pp. 313-318, 2001.

[38] E. Velasquez, P. Lavelle, and M. Andrade, "GISQ, a multifunctional indicator of soil quality," Soil Biology and Biochemistry, vol. 39, no. 12, pp. 3066-3080, 2007.

[39] J. D. Glover, J. P. Reganold, and P. K. Andrews, "Systematic method for rating soil quality of conventional, organic, and integrated apple orchards in Washington State," Agriculture, Ecosystems and Environment, vol. 80, no. 1-2, pp. 29-45, 2000.

[40] R. E. Masto, P. K. Chhonkar, D. Singh, and A. K. Patra, "Soil quality response to long-term nutrient and crop management on a semi-arid Inceptisol," Agriculture, Ecosystems and Environment, vol. 118, pp. 130-142, 2007.

[41] P. J. Gregory, L. P. Simmonds, and C. J. Pilbeam, "Soil type, climatic regime, and the response of water use efficiency to crop management," Agronomy Journal, vol. 92, no. 5, pp. 814-820, 2000.

[42] B. D. Kay and D. A. Angers, "Soil structure," in Handbook of Soil Science, M. E. Summer, Ed., pp. 229-269, CRC Press, New York, NY, USA, 1999.

[43] M. J. Mausbach and C. A. Seybold, "Assessment of soil quality," in Soil Quality and Agricultural Sustainability, R. Lal, Ed., pp. 33-43, Sleeping Bear Press, Chelsea, Mich, USA, 1998.

[44] D. L. Karlen and D. E. Scott, "A framework for evaluating physical and chemical indicators of soil quality," in Defining Soil Quality for a Sustainable Environment, J. W. Doran, D. C. Coleman, D. F. Bezdicek, and B. A. Stewart, Eds., pp. 53-72, Soil Science Society of America, Madison, Wis, USA, 1994.

[45] D. L. Karlen, N. C. Wollenhaupt, D. C. Erbach et al., "Crop residue effects on soil quality following 10-years of no-till corn," Soil and Tillage Research, vol. 31, no. 2-3, pp. 149-167, 1994.

[46] C. A. Seybold, M. J. Mausbach, D. L. Karlen, and H. H. Rogers, "Quantification of soil quality," in Soil Processes and the Carbon Cycle, R. Lal, J. M. Kimble, R. F. Follett, and B. A. Stewart, Eds., pp. 387-404, CRC Press, Washington, DC, USA, 1997.

[47] Statistical Package for Social Sciences, "Release 18.0.," SPSS, 2011.

[48] J. J. Brejda, D. L. Karlen, J. L. Smith, and D. L. Allan, "Identification of regional soil quality factors and indicators: II. Northern Mississippi Loess Hills and Palouse Prairie," Soil Science Society of America Journal, vol. 64, no. 6, pp. 2125-2135, 2000.

[49] R. A. Johnson and D. W. Wichern, Applied Multivariate Statistical Analysis, Prentice-Hall, Englewood Cliffs, NJ, USA, 1992.

[50] J. P. E. Anderson and K. H. Demsch, "Quantities of plant nutrients in the microbial biomass of selected soils," Soil Science, vol. 130, pp. 211-216, 1980.

[51] G. P. Sparling, "Ratio of microbial biomass carbon to soil organic carbon as a sensitive indicator of changes in soil organic matter," Australian Journal of Soil Research, vol. 30, no. 2, pp. 195-207, 1992.
[52] D. S. Jenkinson, "Determination of microbial biomass carbon and nitrogen in soil," in Advances in Nitrogen Cycling in Agricultural Ecosystems, J. R. Wilson, Ed., pp. 368-386, CAB International, Wallingford, UK, 1988.

[53] S. S. Andrews, J. P. Mitchell, R. Mancinelli et al., "On-farm assessment of soil quality in California's Central Valley," Agronomy Journal, vol. 94, no. 1, pp. 12-23, 2002.

[54] R. F. Fisher, "Soil organic matter: clue or conundrum," in Carbon Forms and Functions in Forest Soils, W. H. McFee and J. M. Kelly, Eds., pp. 1-11, Soil Science Society of America, Madison, Wis, USA, 1995.

[55] B. Kaur, S. R. Gupta, and G. Singh, "Soil carbon, microbial activity and nitrogen availability in agroforestry systems on moderately alkaline soils in Northern India," Applied Soil Ecology, vol. 15, no. 3, pp. 283-294, 2000.

[56] Z. Filip, "International approach to assessing soil quality by ecologically-related biological parameters," Agriculture, Ecosystems and Environment, vol. 88, no. 2, pp. 169-174, 2002.

[57] T. Yan, L. Yang, and C. D. Campbell, "Microbial biomass and metabolic quotient of soils under different land use in the Three Gorges Reservoir area," Geoderma, vol. 115, no. 1-2, pp. 129-138, 2003. 

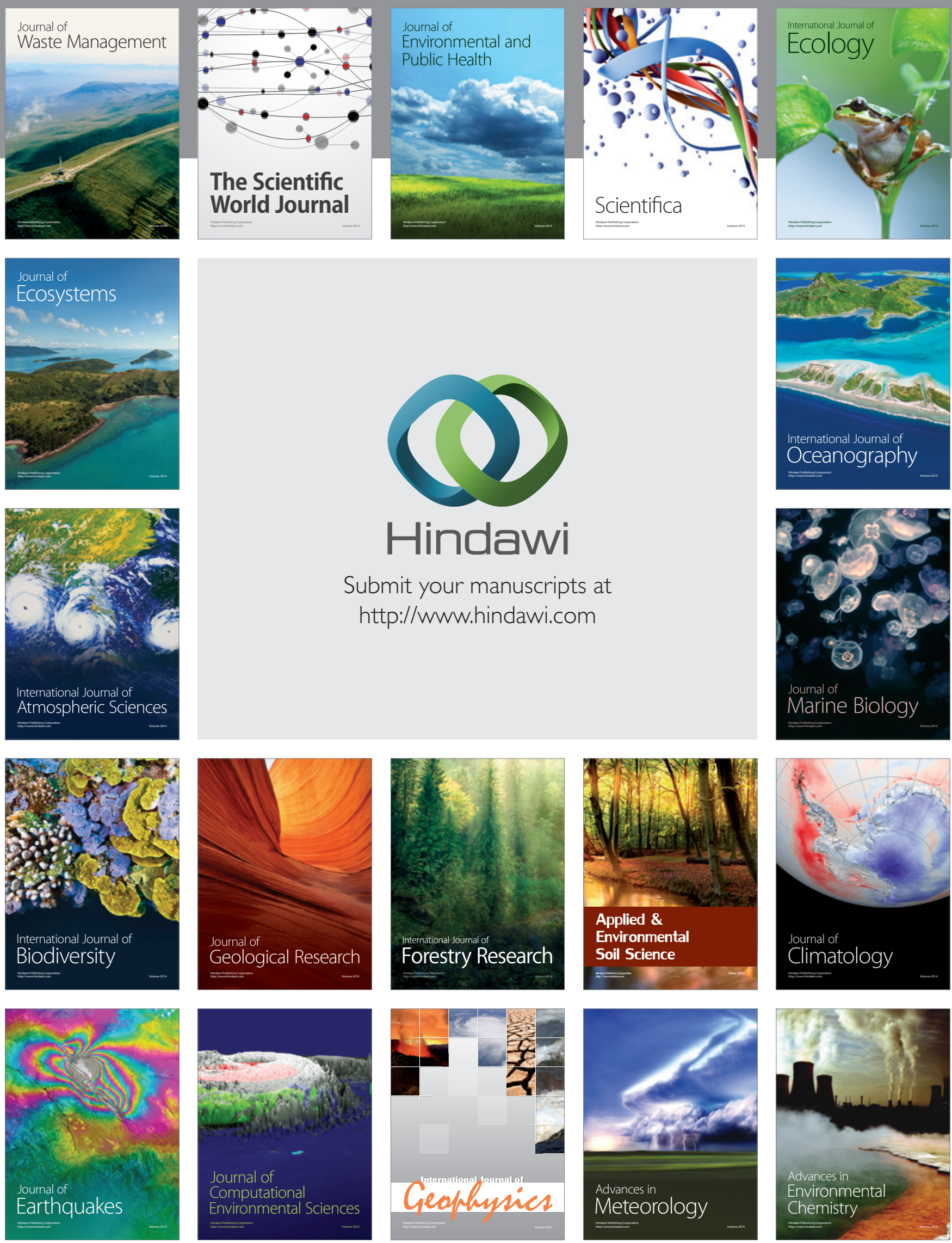